\title{
A PLEA FOR THE PRESERVATION OF RECORDS CONCERNING FISH
}

\author{
BY JACOB REIGHARD, \\ Professor of Zoology, University of Michigan.
}

For five years $I$ have been in charge of the Biological Station of the University of Michigan, situated on Douglas Lake, about fifteen miles south of the Straits of Mackinaw in the Southern Peninsula of Michigan. During this time, more especially during the last year, I have recorded such facts as I could find out about the fish of the lake. In order to study the data collected I have arranged them in tables, one of which is reproduced below :

DATA CONCERNING PIKe (ESOX LUCTUS) OF DOUGLAS LAKE, 1011-1918.

\begin{tabular}{|c|c|c|c|c|c|c|c|c|}
\hline 题悬 & 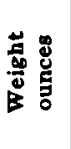 & 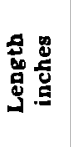 & 品 & 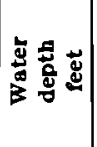 & 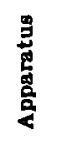 & 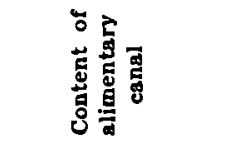 & 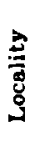 & 岕 \\
\hline 1 & 104 & 20.6 & & 15 & gill & 2 four-inch perch & 18 & $7,8,11$. \\
\hline 2 & 20 & 15 & & $25-90$ & gill & 2 perch, $4 \frac{1}{2} ; 83 / 6$ & 8 & $7,11,11$ \\
\hline 3 & 19 & 19.2 & $\mathbf{m}$ & 4 & eill & fish, not determined & s & $8,3,12$ \\
\hline 4 & 15 & 15.4 & f & 18 & gill & empty & $\mathbf{s}$ & $8,8,18$ \\
\hline 5 & 13 & 14.8 & $\mathbf{m}$ & 12 & gill & fish & 5 & $8,11,12$ \\
\hline 6 & 16 & 15.2 & $\mathbf{m}$ & 12 & gill & flsh & s & $8,12,12$ \\
\hline 7 & 21 & 16.4 & $\mathbf{m}$ & 18 & gill & empty & 5 & 8.19 .12 \\
\hline 8 & 30 & 18 & $\mathbf{f}$ & 26 & gill & empty & 4 & $8,15.12$ \\
\hline 9 & 99.5 & 16.8 & $\mathbf{m}$ & 26 & gill & empty & 6 & $8,15,12$. \\
\hline 10 & 26 & 17 & $\mathbf{m}$ & 26 & gill & empty & 6 & $8,15,12$. \\
\hline 11 & 10 & 12.8 & $f$ & 20 & gill & empty & 6 & $8,15,12$ \\
\hline 18 & 10 & 12.8 & $f$ & 96 & gill & empty & 6 & $8,16,12$ \\
\hline 13 & 18 & 15.6 & f & 26 & gill & empty & 6 & $8,16,12$ \\
\hline 14 & 24 & 17.6 & $f$ & 26 & gill & empty & 6 & $8,20,12$ \\
\hline 15 & 24 & 17.6 & $f$ & 18 & gill & $2 \mathrm{fish}$ & 7 & $8,20,12$ \\
\hline 16 & 28.5 & 17.9 & f & 18 & gill & 2 fish & 7 & $8,20,12$ \\
\hline 17 & 10 & 19.6 & t & 28 & gill & empty & 7 & $8,20,12$ \\
\hline 18 & 10.5 & 18.6 & $\mathbf{m}$ & 25 & gill & empty & 7 & $8,80,12$ \\
\hline 10 & 25 & 17.8 & f & 85 & Eill & empty & 7 & $8,14,12$ \\
\hline 20 & 27 & 18.8 & $\mathbf{m}$ & 10 & gill & ernpty & 3 & $8,14,12$ \\
\hline 21 & 18 & 18.2 & $\mathbf{m}$ & 12 & gill & empty & 5 & $8,18,12$ \\
\hline 22 & 50 & 10.6 & $\mathbf{m}$ & 45 & gill & empty & 6 & $8,18,12$. \\
\hline
\end{tabular}

Lengths are measured from the tip of the anout along the side to the base of the rays of the tail fin. 
By depth of water is meant the distance from the point at which the fish is taken to the surface, which is usually, although not always, the distance from the bottom to the surface. The localities may be indicated, as in the table, by means of numbers which refer to a map or by descriptive terms. It is convenient for purposes of discussion to indicate each fish by a serial number.

A number of interesting facts at once appear from the table. In July and August the pike in this lake are seen to range from a depth of four feet to that of forty-five feet. This depth-range at this season is explained by the fact that below forty-five feet the water contains little or no oxygen so that the pike cannot live there. At other seasons they may range deeper.

The food, so far as it may be learned from so few records, consists entirely of fish. The four fish well enough preserved for identification were perch. These were taken in spite of the spines of their dorsal fins, a hint perhaps to fishermen.

Of the twenty pike whose sex was determined, half were males. The males averaged about three ounces heavier than the females, but the data are not enough to warrant a general statement on this score.

If we represent the length of each fish by a corresponding distance measured along a vertical line and its weight by distance along a horizontal line we may show the length and weight of each by means of a point. Thus in figure one, each inch of length is represented by a space on the vertical line at the left; each ounce of weight by a space on the horizontal line. The intersection of horizontal and vertical lines drawn from the two points thus located gives a point which shows at the same time the length and weight of an individual fish. Thus the point at the extreme right in our figure indicates a fish of 30.6 inches length and 104 ounces weight. The remaining points indicate the lengths and weights of the pike in our table. Through these points we may draw a curve as shown in the figure. This curve 
may be drawn with mathematical precision, but that would require a larger number of points than we have for the pike. The curve in the figure has therefore been merely sketched in. It represents the relation between length and weight of the 22 pike in the table. With sufficient data the relation might be expressed by a curve from which it would be possible to derive an algebraic formula.

The curve shows that as the pike grow longer the length increases less rapidly than the weight. Thus between the lengths of fifteen and sixteen inches there is an increase of nearly four ounces in weight, while between the lengths of twelve and thirteen inches there is an increase of but two ounces in weight. In other words the pike increases in weight about twice as much per unit of length between fifteen and sixteen inches as it does between twelve and thirteen inches.

Such a curve may very well be characteristic of the lake. It may indicate whether the conditions in the lake are favorable to pike, or it may have some other meaning. To see whether the curve has any meaning I attempted to find similar data from which to construct a curve for pike from some other locality. I was unable to find them and so far as I know they do not exist. In Forbes and Richardson's Fishes of Illinois the average length of the pike in Illinois is given as 36 inches and the average weight as 80 ounces, but it is not stated whether these averages are made from measurements or are mere estimates. If the point for a pike of 36 inches and 80 ounces is indicated on the chart it is seen, as shown by the broken line, to fall well above the curve for the pike of Douglas Lake. A hypothetical curve sketched through this point is seen to have a different form from the Douglas Lake curve. It rises more steeply and indicates a less rapid increase of weight per unit of length. In other words the pike represented by such a curve would be longer for a given weight. In Douglas Lake a pike of 80 ounces should be about 26 inches long, while in Illinois it is said to be on the average 36 inches 


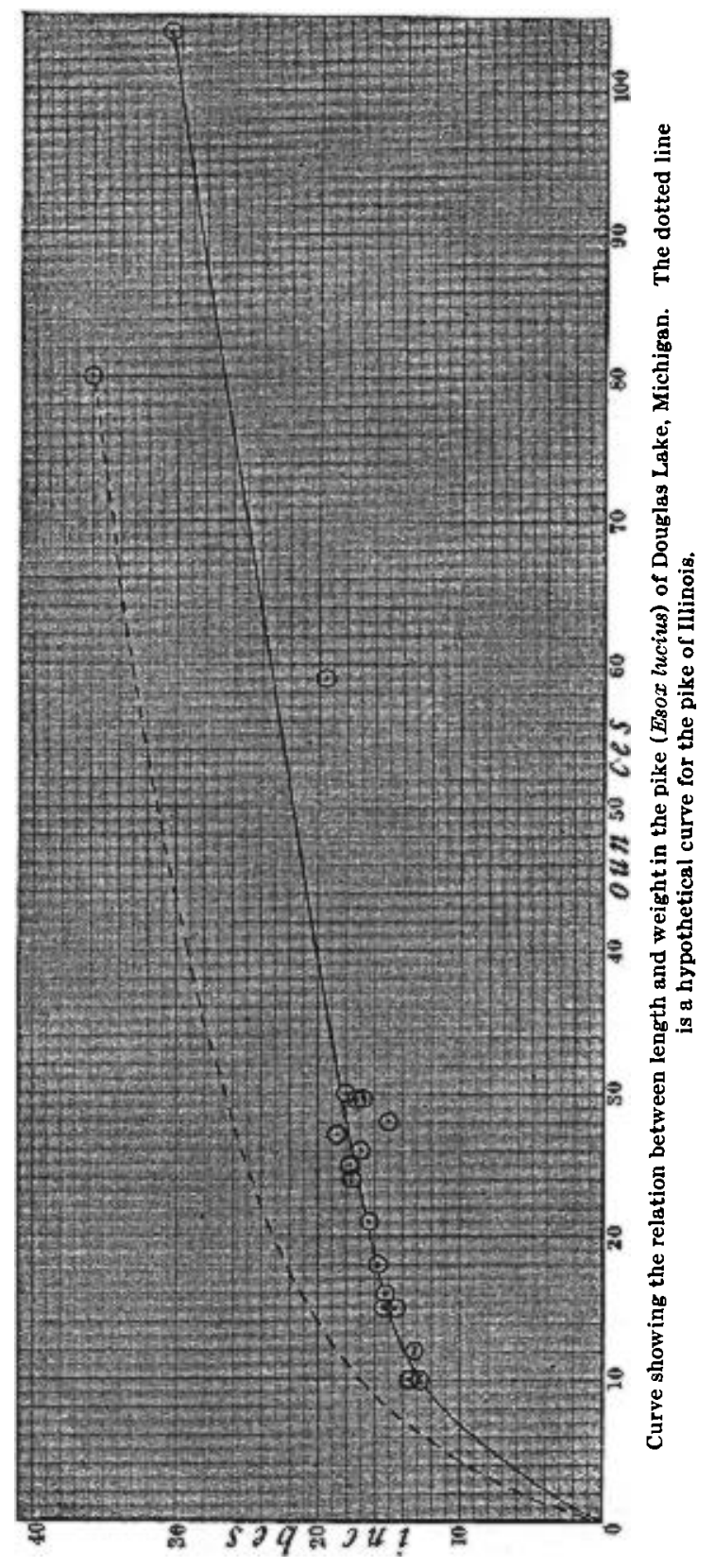


long. It is possible that such a curve represents conditions favorable or unfavorable according to its form, but at present we have no data from which to determine whether this is true or not.

It seems to me important that data such as are included in the table here shown be accumulated. By means of them we should learn much of the conditions under which our various fishes live. In addition to the data included in our table there might be added others on parasites, on breeding habits and breeding seasons, conditions of the sexual glands, character of bottom and of vegetation at the point where fish are taken, and possibly on the temperature of the water. A table of the form here indicated is shown below. It is suggested that a data blank of suitable form with instructions for its use be prepared and distributed to members of this society. This might be done by the United States Bureau of Fisheries and the blanks, properly filled, might be returned to the Bureau. In this way information about the conditions under which fish live would be gradually accumulated at Washington. Whenever the observer was uncertain as to a species of fish or the character of stomach contents, the specimens might be forwarded for identification. A study of the accumulated data would certainly add much to our wholly inadequate knowledge of the natural history of our fishes.

FORM SUGGESTED FOR USE IN RECORDING DATA CONCERNING FISH

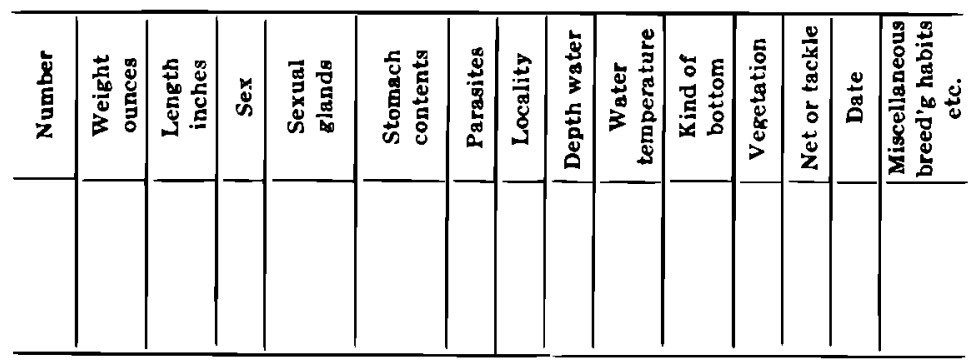

1. Each fish should be given a serial number and the data concerning it entered in the appropriate columns opposite its number. 
2. Lengths should be measured along the middle of the side from the tip of the snout to the base (not tip) of the tail fin.

3. By depth of water is meant the number of feet from the sarface to point at which fish was taken.

4. Under the locality should be indicated name of body of water, and its location, and point in it at which fish was taken. 